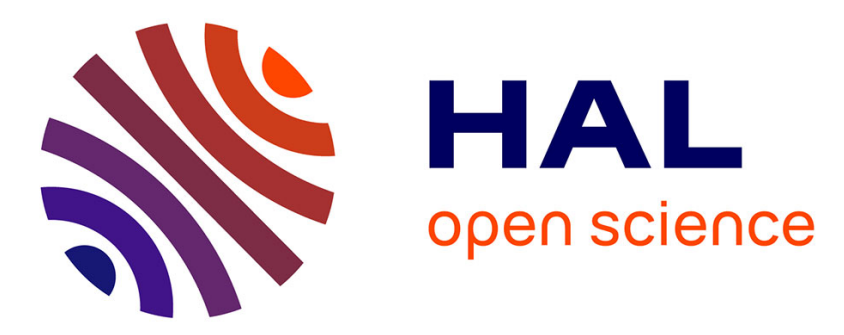

\title{
MODELING OF COLD WALL CHEMICAL VAPOR DEPOSITION REACTORS (FOR SEMICONDUCTOR FABRICATION)
}

\author{
M. Pons, R. Klein, C. Arena, S. Mariaux
}

\section{- To cite this version:}

M. Pons, R. Klein, C. Arena, S. Mariaux. MODELING OF COLD WALL CHEMICAL VAPOR DEPOSITION REACTORS (FOR SEMICONDUCTOR FABRICATION). Journal de Physique Colloques, 1989, 50 (C5), pp.C5-57-C5-65. 10.1051/jphyscol:1989510 . jpa-00229533

HAL Id: jpa-00229533

https://hal.science/jpa-00229533

Submitted on 1 Jan 1989

HAL is a multi-disciplinary open access archive for the deposit and dissemination of scientific research documents, whether they are published or not. The documents may come from teaching and research institutions in France or abroad, or from public or private research centers.
L'archive ouverte pluridisciplinaire HAL, est destinée au dépôt et à la diffusion de documents scientifiques de niveau recherche, publiés ou non, émanant des établissements d'enseignement et de recherche français ou étrangers, des laboratoires publics ou privés. 


\title{
MODELING OF COLD WALI CHEMICAL VAPOR DEPOSITION REACTORS (FOR SEMICONDUCTOR FABRICATION)
}

\author{
M. PONS" * R. KLEIN, C. ARENA and S. MARIAUX* \\ D. LETI/IRDI, CEA, CEN/G, 85X, F-38041 Grenoble, France \\ 'DT21, chemin des Prèles, F-38240 Meylan, France \\ * S2MC/CNRS UA-413, ENSEEG, INPG, BP. 75, F-38402 st Martin d'Hères, \\ France
}

RESUME - Les phénomènes survenant au cours du dépôt chimique à partir d'une phase vapeur resultent du couplage des transferts de chaleur et de matière et de la réaction chimique donnant lieu au dépôt. La résolution du système d'équations differentielles requiert l'emploi de techniques numériques. Nous avons au D-Leti utilisé Flux-Expert, un logiciel faisant appel aux techniques éléments finis pour simuler le comportement des réacteurs de D.C.P.V. Ce logiciel peut aisément évoluer lorsque de nouvelles équations sont ajoutées ; il est de plus très convivial. A l'heure actuelle, nous ne présentons que des résultats obtenus pour des géométries axisymétriques ; des simulations tridimensionnelles sont en cours de développement. Le but du travail présenté est de montrer que cet outil peut permettre la conception, l'évaluation et la prédiction des réacteurs.

\begin{abstract}
Basic chemical vapor deposition concepts involve fluid mechanics, heat and mass transfers associated with both gas phase and surface chemical reactions. Powerful numerical techniques are necessary to solve the relevant equations. Flux-Expert is a general finite element program which is commercially available; the adaptation of this general purpose sof tware package to the modeling of CVD reactors has been developed at the D-Leti. The original software can easily be upgraded with additional new equations ; it is a fully interactive, menu driven program with built in graphics.

At the present time, our software is designed to simulate only two dimensionnal axisymmetric problems (cylindrical coordinate systems). A three dimensional version is in progress. The purpose of this work is to explore the performance of CVD reactors, optimize the possibilities of existing reactors, provide users with a helpful tool for the development of new reactor configurations and the prediction of related process parameters.
\end{abstract}

\section{1 - INTRODUCTION}

The design of CVD reactors involves cross-disciplinary sciences which will allow a complete description of the phenomena /1/. In fact, the performances of CVD are depending on a wide range of variables. The geometric configuration of the reactor, the operating conditions are intimately related to the kinetics of the film growth $/ 1-9 /$. It is important to note that, for the most part, the design of the industrial equipment has been made empirically and cannot guarantee optimum conditions $/ 6 /$. For these reasons, the current trend is to develop models to describe the deposition process and the interdependence of the basic physical phenomena. The predictions which come from these models are limited (perhaps except for the Si deposition) by an incomplete knowledge of the chemical phenomena (chemical reactions either in the gas phase or on the substrate) $/ 1 /$. In order to reach some insight, like in others studies $/ 1-16 /$, we have adapted the general finite element code Flux-Expert $/ 17 /$ to the heat and mass transfers CVD problems. We have chosen a general code because CVD problems are numerous; the code must be easily modified and upgraded. At the present time, our software is designed to simulate only two dimensional problems (cylindrical coordinate systems). The three dimensional adaptation is in progress, especially for the design of tubular reactors used for the low temperature deposition of silicon oxide and for the modeling of injector geometries.

The purpose of this work is to provide users (engineers and even students) with (i) a helpfull tool for the development of new reactor configurations, (ii) the prediction of optimal operating conditions and (iii) general knowledge of CVD phenomena and problems. With built in graphics and fully interaction, this software may easily be used by a broad range of users.

After the description of the used code and of the numerical procedures, we present its potential uses for the design of axisymmetrical reactors. This type of single wafer reactors is very attractive for numerous microelectronic applications $/ 18 /$.

\section{2 - THE ÁVAILABILITY OF SOFTWARE PACKAGES}

Many powerful and large scale, general purpose finite element or finite difference codes have been 
developed and are commercially available. In the modeling of solids and structure the interactive graphic accelerates popular use of finite element methods because the pre- and post-processing give users easy access $/ 19 /$. For fluid mechanics, heat and mass transfer coupled problems, to our knowledge, only few software packages are easily available. The Fidap finite element code (USA) allows solution of almost all incompressible fluid mechanics problems even coupled with heat transfer. Phoenics finite difference code (G.B.) allows solution of almost all heat and mass transfer problems and we think that it could solve CVD problems. In France, Modulef and Flux-Expert, general purpose finite element codes, allow solution of some chemical engineering problems. However, the equations to be solved must be transformed to a finite element formulation. We have chosen Flux-Expert. In this software package, some chemical engineering equations which are compatible with the finite element formulation can be solved. Consequently, it may be used (i) obviously for educational purpose, (ii) to design reactors for known chemical phenomena (iii) to reach general insight about new phenomena.

\section{3 - THE EQUATIONS AND THE NUMERICAL PROCEDURE}

The CVD process involves momentum, mass, energy and species balance $/ 1,20 /$. We only consider the stationary case pecause the film growth rate $\left(1 \mu \mathrm{m} . \mathrm{s}^{-1}\right)$ is generally slow compared to the gas velocities $\left(1 \mathrm{~m} . \mathrm{s}^{-1}\right) / 21 /$. As. in the most cases the reactants are diluted in the carrier gas $\left(\mathrm{H}_{2}\right.$, Ar, $\mathrm{N}_{2} \ldots$ ) it is possible to remove the dependence of the flow on the species balance; the concentration field of the reactive species involves a negligible effect on the physical properties which can be assumed to be those of the pure carrier gas. The momentum, energy and mass balance are first solved. We obtain the velocities, pressure and temperature fields which become an input to species balance equations. The consumption of the reacting gas (i.e. the deposition kinetic) is a boundary condition on the reacting areas. Generally, for CVD experiments the flow is laminar /1-16/. Table 1 displays the general equations to be solved. Because of the assumption of dilute reactants the heat of the reaction will be negligible except in some systems with oxidation (i.e. $\mathrm{SiO}_{2}$ deposition). The consumption of the reacting gas by reactions in the homogeneous phase is not taken into account in the equation (4) but should be for special applications. The deposition calcutations were performed with an axisymmetrical geometry.Table 2 shows the boundary conditions. In this example, the reactor walls and the wafer susceptor are water cooled. This configuration is desirable to avoid wall deposition. Configurations. with insulated walls and/or with inductive heating will not be presented in this paper for better clarity. The wafer $(R=5 \mathrm{~cm})$ is attached to the heater. The distance between the wafer and the inlet will be called $Z$ the outlet radius 1 and the inlet radius $L$.

The physical and chemical properties of the mixture results from experimental data or from statistical calculations $120,22-23 /$. They can generally be expressed as a function of temperature and pressure /see for example $21 \%$

I1 CONTWUITY EOUATION FOR THE MASS

$\operatorname{div}(p \cdot \vec{v})=0$

(2) CONTWUTY EQUATION FOA THE MONENTUM

$$
\begin{aligned}
& p \cdot(\vec{v} \cdot \overrightarrow{\operatorname{grad}} \vec{v})=\operatorname{div}(\vec{\tau})+\rho \cdot \vec{z} \\
& \bar{\tau}=\mu \cdot(\operatorname{grad} \vec{v}+\operatorname{grad} \vec{v})-(2 / 3 \cdot \mu \cdot \operatorname{div} \vec{v}+P) \cdot I
\end{aligned}
$$

(3) CONTWUTY EOUATION FOR THE ENERGY

$$
\text { p.C. }(\vec{V} \cdot \overrightarrow{\operatorname{grad}} \mathrm{T})=\operatorname{div}(k \cdot \overrightarrow{\operatorname{grad}} \mathrm{T})
$$

[4] CONTWUTY EOUATION FOA THE COMPONENT $A_{i}$

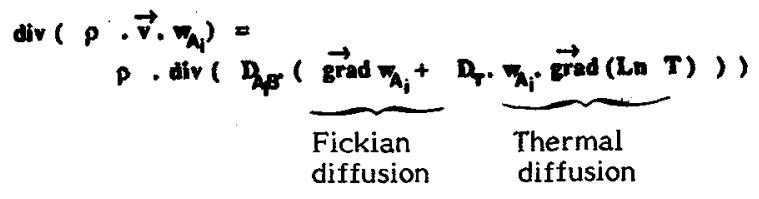

Table 1 : General equations 


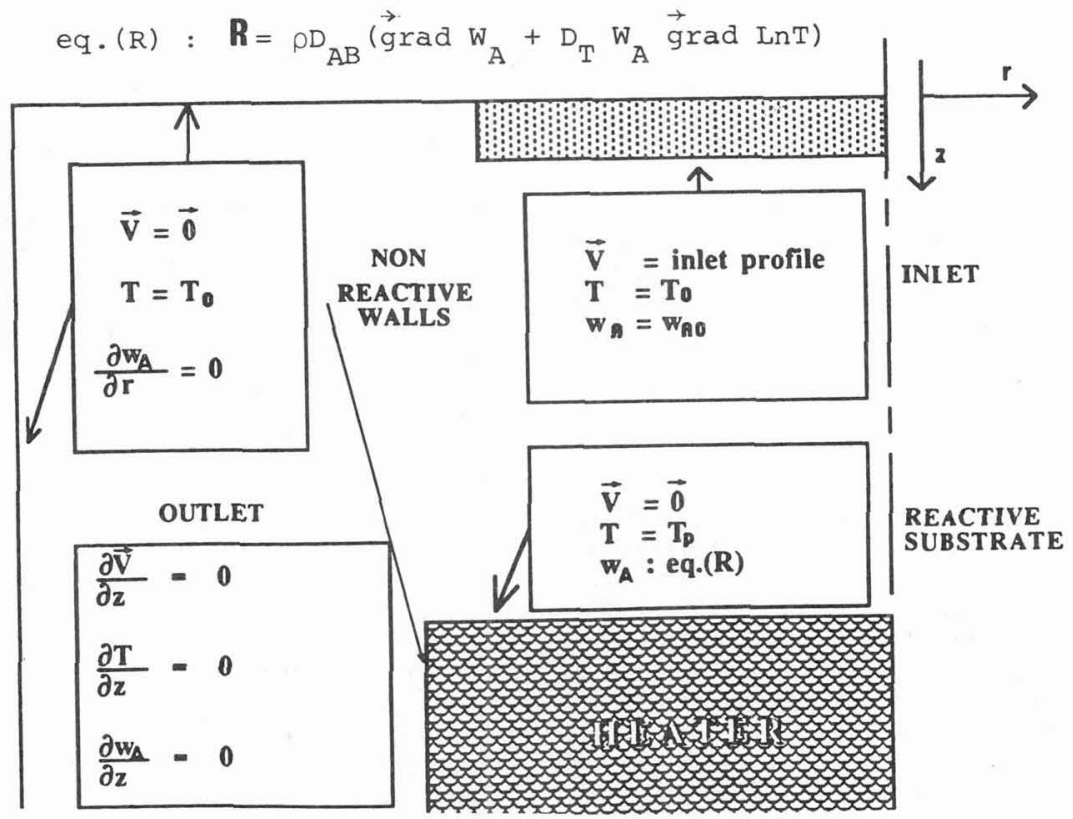

Table 2 : Boundary conditions for a stagnation point flow reactor.

The modeling equations, the boundary conditions and the variable physical properties form a complex set of partial differential equations. The Galerkin finite element method was chosen to solve this problem. Each equation is projected on polynomial basis functions. A mixed order polynomial approximation was used ; for the components of velocity, temperature and concentration the order 2 was chosen, for pressure the order 1. The stability of the method depends on the element dimensions and the characteristic number which is the ratio of advection to diffusion. The limit is $\operatorname{Re}=2$ on each element. This limit is, at the present time, acceptable for the most part of CVD experiments. The complete set form of nonlinear algeabric equations can be found in Ref.24. The finite element method is a powerful means of solving complex equations; no simplifying assumptions are necessary, but extensive computation time is required and many simulations are necessary to reach a general insight $/ 5 /$.

Table 3 summarizes the resolution scheme for cold wall reactors.

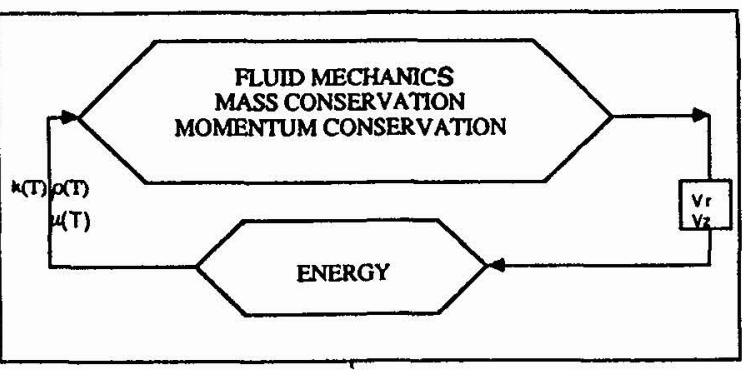

(a)

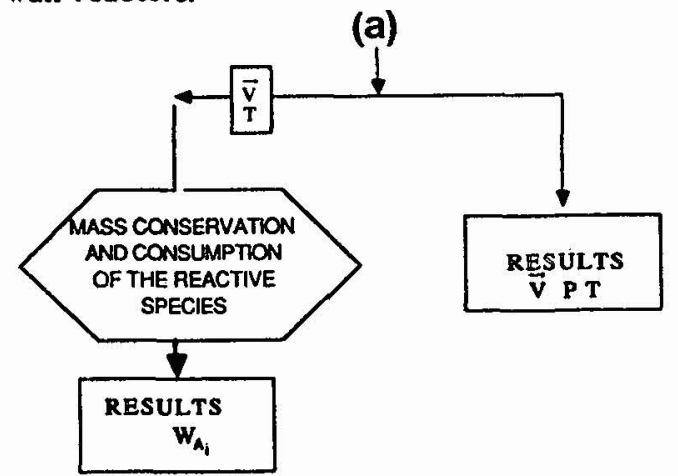

Table 3 : Resolution scheme for cold wall reactor.

This sofware allows to calculate deposition rates from deposited flux under the following conditions :

* stationary cas ; laminar flow

* isothermal/non isothermal reactors

* concentration and thermal gradient driven diffusion

* surface reaction or diffusion controlled deposition

* any inlet flow profile

* variable physical properties ; axisymmetrical geometry 


\section{4 - SIMULATION RESULTS}

Our aim is not to show results for a special problem but to demonstrate that our software can solve a wide range of problems, at the present time, for axisymmetrical cylindrical reactors ; so, the results, as in some recent studies $/ 1-15 /$, will be displayed with dimensionless characteristic numbers.

Although the goal of the simulation is to predict the deposition rate and the thickness homogeneity of the film, we have separated the thermal gas flow study from the deposition rate study. Indeed, temperature gradient driven recirculations arising from operating conditions must generally be avoided because they limit the deposition uniformity and they can bring the by-products back into contact with the wafer. We have numerically explored the geometric and operating conditions that would lead to a flow field free of recirculations. From the operating conditions previously defined, we have calculated the deposition rate.

\section{4-1 Thermal effects}

For hydrogen carrier gas, Reynolds numbers (see table 4 for the definition) from 1 to 10 have been chosen for the calculations; they reflect realistic CVD conditions. The different geometries presented are not always common but they are technologically possible. Figure 1 shows an example of recirculation arising from thermal gradients for an atmospheric pressure reactor. With these conditions, the flow is dominated by a buoyancy driven recirculation cell above the substrate. The dimensionless number which may characterize the magnitude of this effect is the ratio $\mathrm{Gr} / \mathrm{Re}^{2}$ (see table 4); it can be used as a diagnostic factor/2/. It represents the ratio of natural convection velocity squared to the forced convection velocity squared. The dimensionless number $G$ (see table 4) defined by Jensen and al. /21/ can characterize, for a given Re number, the magnitude of the thermal effects in relation to the inlet-plate distance $Z$ (note that if $Z=L, G r=G .(\Delta \rho / \rho)$. According to Wahl $/ 2 /$, the influence of gravity on the gas flow can be neglected if $\mathrm{Gr} / \mathrm{Re}^{2}<\mathrm{C}_{0}$, where $\mathrm{C}_{0}$ is a complex function of the previously selected geometric parameters; nevertheless $C_{0}$ seems difficult to calculate. It is the reason why we have chosen for the stagnation point reactor to present the transition between the different flow features with the number $G$; it may give some insight more easily.

The intent is to lower or avoid thermal recirculation. The first solution would be to increase the flow rate (i.e. to decrease $\mathrm{Gr} / \mathrm{Re}^{2}$ ) ; at atmospheric pressure, even with hydrogen carrier gas, high flow rate are required (more than $51 . \mathrm{mn}^{-1}$ STP). The second solution is to diminish the wafer-inlet length (see the cubic dependence of $G$ on the plate separation $Z$ ). We have shown that it is necessary to lower the aspect ratio down to 0.3 to avoid recirculation. Figure 2 is an example of existing reactors whose aspect ratio have been decreased. The third solution is to decrease the density of the gas and eventually the aspect ratio. As hydrogen carrier gas was chosen, the only way to decrease the density is to reduce the pressure (figure 3 ).

$$
\begin{aligned}
& \text { Re }=\rho_{0} v_{0} L / \mu_{0} \\
& F r=v_{0}^{2} / g L \\
& G=\rho_{0}^{2} g \mathrm{z}^{3} / \mu_{0}^{2} \\
& \mathrm{~A}=\mathrm{z} / \mathrm{R} \\
& \mathrm{IA}=\mathrm{L} / \mathrm{R} \\
& \mathrm{PA}=\mathrm{I} / \mathrm{R} \\
& \mathrm{Gr}=\mathrm{\rho gLL}^{3} \Delta \rho / \mu_{0}^{2}
\end{aligned}
$$

Table 4 : Dimensionless numbers 

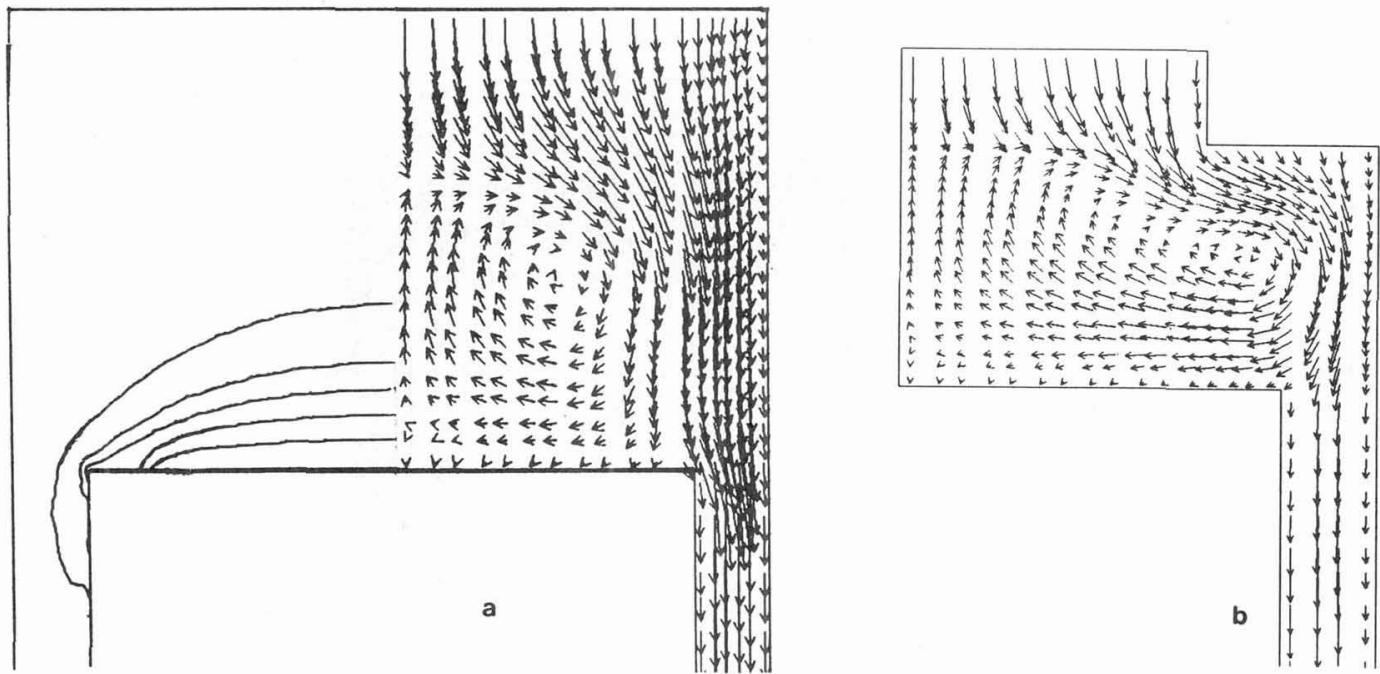

Fig. 1 - Typical velocitiy field and işotherms for $\mathrm{H}_{2}$ flow in a vertical reactor (1 1. $\mathrm{mn}^{-1}$ at the mass flow); $\mathrm{P}=10^{5} \mathrm{~Pa}$

(a) $\operatorname{Re}=2 ; A=1.5 ; \mathrm{IA}=1.1 ; \mathrm{PA}=0.25 ; \mathrm{G}=187000$

(b) $\operatorname{Re}=2 ; A=0.65 ; \mathrm{I} A=0.8 ; \mathrm{PA}=0.25 ; \mathrm{G}=12000$

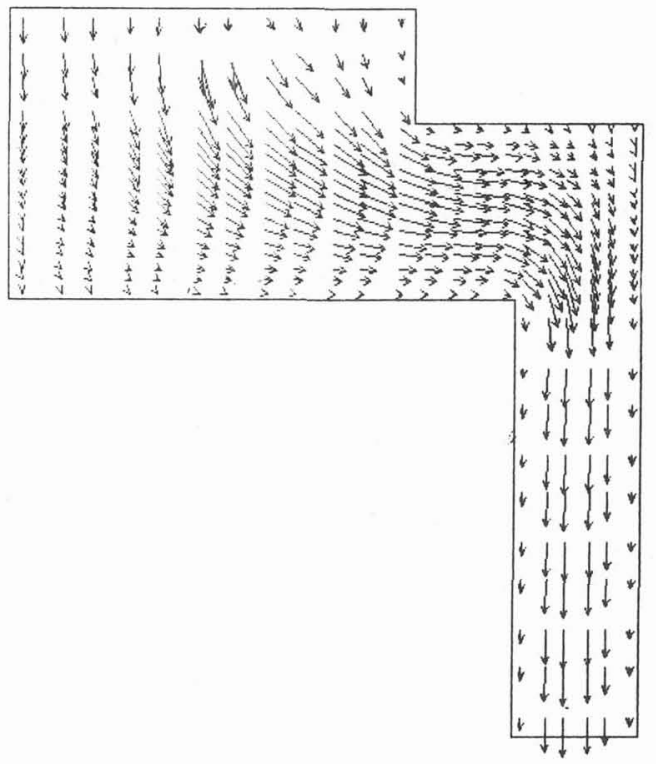

Fig. 2 - Solution of the thermal effects : $Z$ is lowered (i.e. G)

1 I. $\mathrm{mn}^{-1}$ STP ; $\mathrm{P}=10^{5} \mathrm{~Pa}$

$\operatorname{Re}=2 ; \mathrm{A}=0.3 ; \mathrm{IA}=0.8 ; \mathrm{PA}=0.25 ; \mathrm{G}=1500$ 


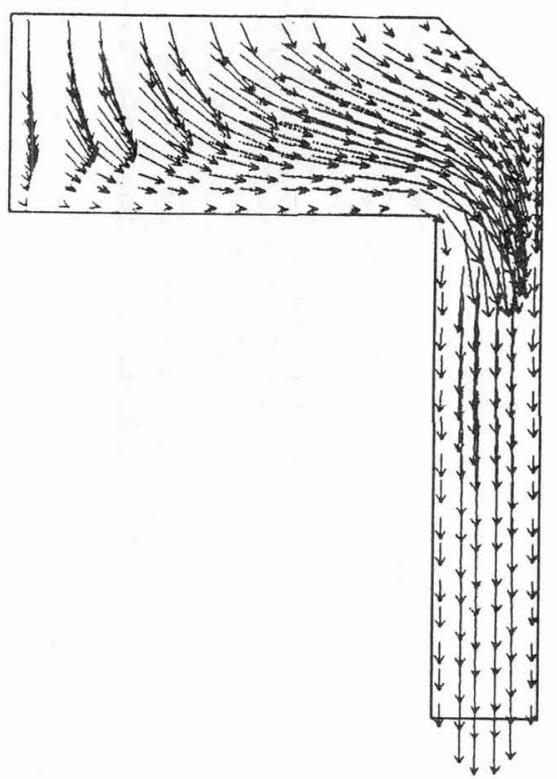

Fig 3 - Solution of the thermal effects : pressure is reduced (i.e. G and Gr) 1 1. $\mathrm{mn}^{-1} \mathrm{STP} ; \mathrm{P}=5.10^{3} \mathrm{~Pa}$ $\operatorname{Re}=2 ; A=0.5 ; \mathrm{IA}=0.8 ; \mathrm{PA}=0.25 ; \mathrm{G}=20$

A diagnostic can be made using the $G$ ratio. For an inlet flow rate of $11 . \mathrm{mn}^{-1} \mathrm{STP}$, if the ratio is lower than 2000 the flow is forced convection dominated; if $G$ is higher than 2000 natural convection appears. For higher inlet flow rates this critical value is higher. These results are in good agreement with the literature $/ 1-2 /$.

We are able to predict, for realistic CVD conditions, a flow free of thermal gradient driven recirculation. In general, for low pressure reactors, with low molecular carrier gas, if the aspect ratio is lower than 1 , no recirculation is found. For atmospheric pressure reactors, without using prohibitive flow rates, the aspect ratio must be decreased to avoid the thermal effects. It is important to note that for nitrogen or argon carrier gas, it is much more difficult to solve this problem $/ 21 /$. The thermal gradient is steeper and the influence of gravity is increased. If the substrate is heated by induction instead of by a heater, thermal effects are also found in the exit area. We have shown that by narrowing the outlet region (i.e. decreasing the magnitude of PA down to 0.2 ) recirculation can be lowered or eliminated. Jensen and al. $/ 21,25 /$ have also shown that the thermal effects are lowered by inverting the reactor.

\section{4-2 Film homogeneity}

Our aim is to predict the condition leading to a uniform deposition (homogeneity less than $5 \%$ ) over the wafer. It is obvious that the design of the reactor will be all the more difficult as the substrate is large. Although it is possible to obtain a uniform deposition in a mixed flow regime (natural and forced convection) by a proper selection of $\mathrm{G}$ or $\mathrm{Gr} / \mathrm{Re}^{2}$, it is a much simpler task to specify pure forced convection. The mixing action of the vortices is to be avoided since mixing will bring the by-products of the reaction back into contact with the wafer, rather than sweeping them out of the reactor $/ 6 /$.

The rate flow and temperature files acccording to table 3 scheme, were injected in the species balance equations. The results have led to obtain concentration profiles according to the consumption mode of the reacting species. As previous studies $/ 1,10,13 /$ have shown that thermal diffusion cannot be neglected in modeling CVD, we consider only the results where thermal diffusion was included. The major effect of thermal diffusion is generally to lower the deposition rate (i.e. the deposited flux on the reacting areas).

Numerous kinetic schemes can be used (i.e. $R$ is a function of the species concentration; the simpliest form is $\mathrm{R}=\mathrm{kw}, \mathrm{k}$ is the rate constant). For diffusion limited deposition, the rate constant has been chosen sufficiently large; according to Moffat and Jensen $/ 25 /$, it is a better approach than setting the partial pressure of the reacting gas to zero at the wafer surface. 
When surface kinetics control the reaction (generally at low temperature and /or pressure) an uniform distribution ( $5 \%$ ) was found. When complex kinetics, involving gas phase reactions, control the deposition rate, homogeneity may be altered. The effects of unsaturated species are not described here. With the previous results concerning natural convection, several design guidelines or rules of thumb may be developed. For example, a contribution to the optimization of the selectivity in a tungsten CVD reactor $/ 6 /$ can proceed from these trends; the use of (i) a cold wall reactor, (ii) $\mathrm{H}_{2}$ carrier gas, (iii) low pressure, (iiii) high gas velocities leads to a reactor with no wall growth, with no recirculation, thus free of by-products in the reacting area. It must be noted that for the most part these rules have already been incorporated in commercial reactor design. In the case of tungsten, these rules are required but they are not sufficient $126 /$. In the mass transfer limited regime (generally at higher temperature and/or pressure) non linear interactions exist between buoyancy, viscous and inertia terms; multiple flow fields leading to uniform films could be predicted. Figure 4 shows the reduced growth rate for typical configurations. Reactor (a) leads to an increase of the thickness near the outer edge since (i) buoyancy dominates the tranport and (ii) the diffusion layer is thinned at the heater edge by a large flow. For lower values of $\operatorname{Re}(\operatorname{Re} 0.1)$ an opposite profile has been found because the reactive gas is depleted along the surface. Reactor (b), due to its small aspect ratio is forced convection dominated; the film thickness decreases away from the center of the wafer, except near the edge due to the bending of the flow. Reactor (c), a low pressure reactor, obviously leads to the more uniform profile since the diffusion coeficient is increased and the deposition rate lowered. It is important to note that the most part of actual vertical CVD reactors rarely have the wide inlets $(\mathrm{I} A=0.8$ to 1$)$ used in the above calculations. Generally, a thin tube as inlet is used and the aspect ratio is often greater than 1 . With these configurations, homogeneity is never achieved $/ 1 /$. We have shown, with selected examples, some relationships existing between the performances (i.e. uniformity) and the operating conditions (temperature, flow patterns, rate limiting process...) ; others technological problems, as for example the temperature homogeneity of the wafer were not taken into account $/ 26 /$.

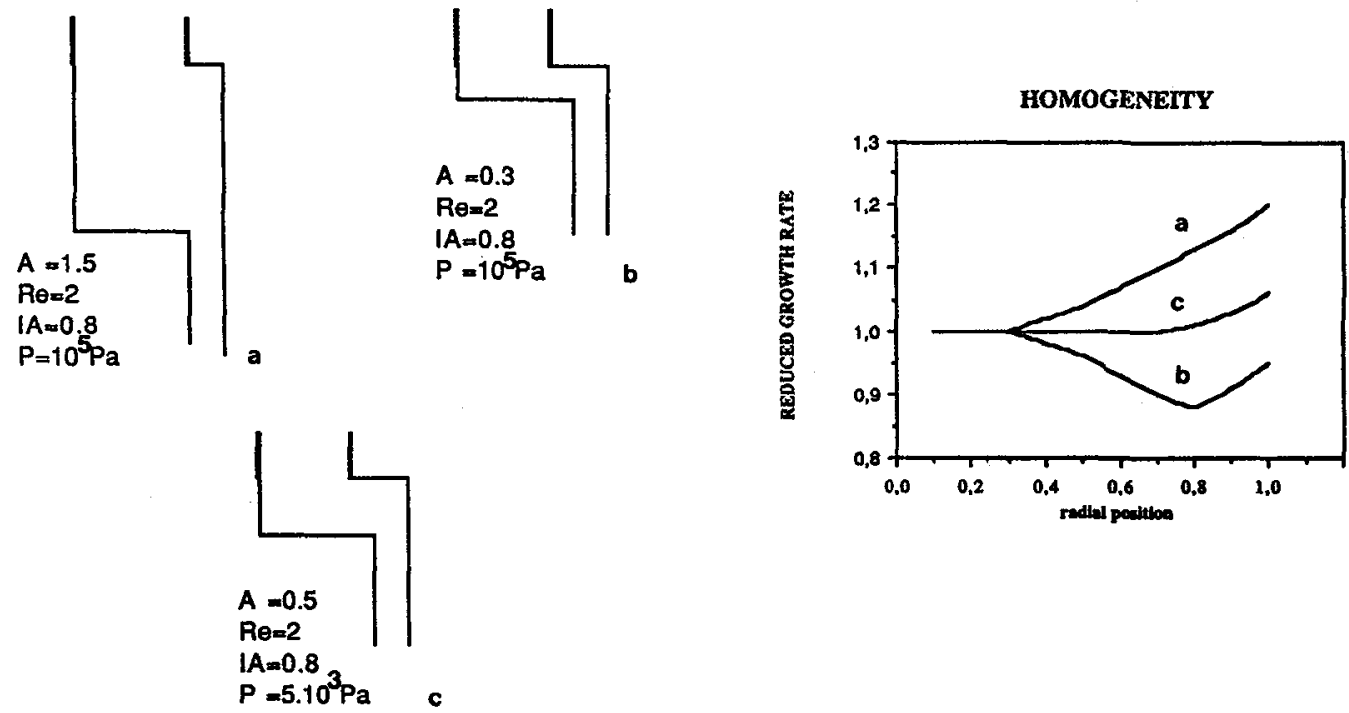

Fig 4 - Homogeneity of the film

\section{5 - CONCLUSION}

The presented calculations depict the influence of the design on the technological performances of axisymmetrical reactors. Numerical models may provide a complete description of the transport processes. But, even with the best numerical models, there is too much lack of data in growth chemistry and in the values of physical constants to reach the absolute growth rates a priori. Therefore, they allow to reach a general insight into the physical processes and to predict the uniformity of the film. This code obviously cannot solve all the problems found in CVD but it may be a starting point for future development. 


\section{REFERENCES}

/1/ Jensen, K.F., Chem. Eng. Sci., 42 (1987) 923

12/ Wahl, G., Thin Solid Films, 40 (1977) 13

13/ Moffat, H.K., Jensen, K.F., J. Electrochem. Soc., 135 (1988) 459

141 Kisker, D.W., Mc Kenna, D.A., Jensen, K.F., Mat. Lett., 6 (1988) 123

151 Field, R.J., Scholz, F., J. Crystal Growth, 88 (1988) 371

16) Raupp, G.B., in Wells, V.A. (ed.) Tungsten and Other Refractory (Metals for VLSI Applications IIl, Material Research Society, Pittsburg, (1988) 15

17/ Vinante, C, Bertrand, J., Couderc, J.P., in R. Porat (ed.) Proc. 6th European Conference on Chemical Vapor Deposition, Jerusalem, Israël, 29 march-3 april 1987, (1987) 42

18/ Coltrin, M., Kee, R.J., Miller, J.A., J. Electrochem. Soc., 129 (1982) 1627

19/ Rebenne, H., Pollard, R., J. Electrochem. Soc., 132(8) (1985) 1932

/10/ Rosemberg, F., in G.W. Cullen, J.H. Blocher (eds.), Proc. 10th International Conference on Chemical Vapor Deposition, The Electrochemical Society Pennington, NJ, 87-8 (1987) 11

111/ Wahl, G., Schmaderer, F., Hubler, R., Weber, R., idem ref. 10, 87-8 (1987) 42

/12/ Lee P., Mc Kenna D., Kapur D., Jensen K.F., J. Crystal Growth, 77 (1986) 120

113/ Rebenne, H., Pollard, R., J.Am. Cer. Soc., 70(12) (1987) 907

114/ Roenigk, K.F., Jensen, K.F., J. Electrochem. Soc., 134(7) (1987) 1777

115/ Wilke, T.E., Turner, K.A., Takoudis, C.G., Chem. Eng. Sci., 41(4) (1986) 643

116/ He, Y., Sahai, Y., id ref 10, 87-8 (1987) 193

/17/ Flux-Expert, DT2l, Meylan, France

/18/ Wahl, G., Schmaderer, F., Huber, R., in Porat (ed.) Proc. 6th European Conference on Chemical Vapor Deposition, Jerusalem, Israël, 29 march-3 april 1987, (1987) 50

119/ N. Kikuchi, Finite Element Method in Mechanics, Cambridge University Press, 1987

120/ Bird, R.B., Stewart, W.E., Lightfoot, E.N., Transport Phenomena, Wiley, NY, 1960

121/ Houtman, C., Graves, D.B., Jensen, K.F., J. Electrochem. Soc., 133 (1986) 961

122/ Reid, R.C., Sherwood, T.K., The properties of Gases and Liquids, Mc Graw Hill, NY, 1966

123/ Encyclopedie des Gaz (1'Air Liquide), Elsevier, 1976

124/ Mariaux, S., Rapport DT2I, Meylan, France, January 1988

125/ Moffat, H., Jensen, K.F., J. Crystal Growth, 77 (1986) 108

126/ Papapietro, M., Arena, C., Noel, P., to be published

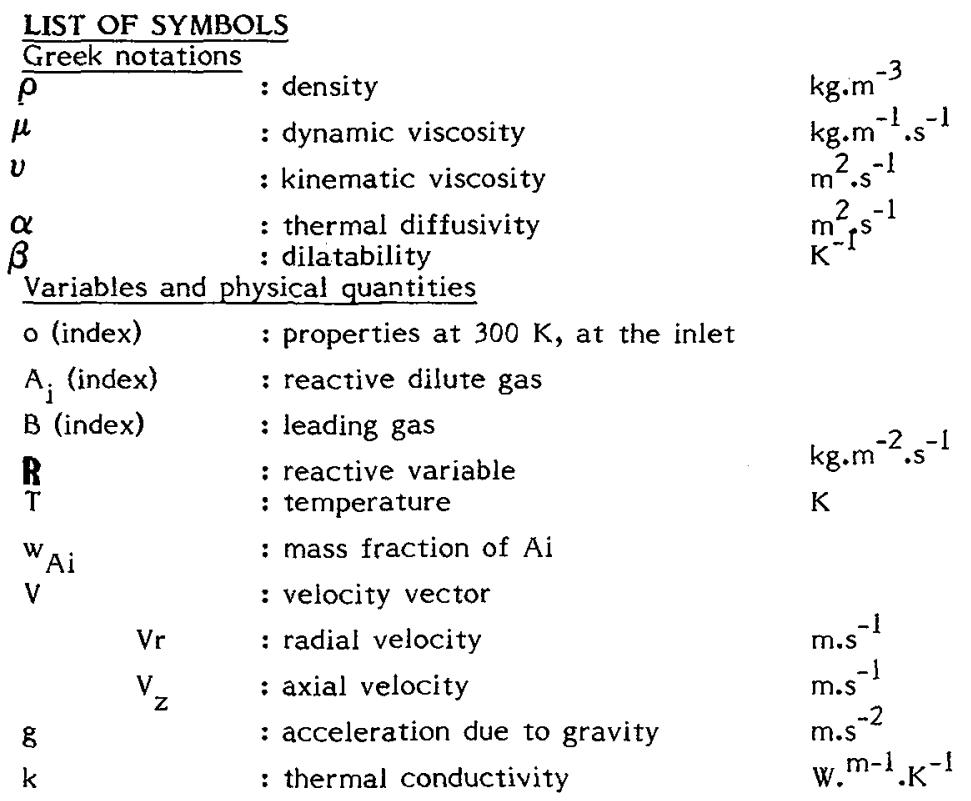




$\begin{array}{ll}\mathrm{P} & \text { : pressure } \\ \mathrm{C} & \text { : heat capacity } \\ \mathrm{D}_{\mathrm{AB}} & \text { : binary diffusion coefficient } \\ \mathrm{D}_{\mathrm{T}} & \text { : thermal diffusion coefficient } \\ \mathrm{M} & \text { : molar mass } \\ \mathrm{R} & \text { : ideal gas law constant }\end{array}$

$\mathrm{kg} \cdot \mathrm{m}-1 \cdot \mathrm{s}^{-2}(\mathrm{~Pa})$

J.kg ${ }^{-1} \cdot \mathrm{K}^{-1}$

$\mathrm{m}^{-2} \cdot \mathrm{s}^{-1}$

Dimensionless numbers

$\begin{array}{ll}\mathrm{Gr} & : \text { Grashof } \\ \mathrm{Re} & \text { : Reynolds } \\ \mathrm{Fr} & : \text { Froude } \\ \mathrm{G} & : \text { Gravity number } \\ \mathrm{Sh} & : \text { Sherwood } \\ \mathrm{A} & \text { : aspect ratio } \\ \text { JA } & \text { : inlet aspect ratio } \\ \text { PA } & \text { : pumping aspect ratio }\end{array}$

Reactor dimensions

$\begin{array}{lll}Z & : \text { inlet-substrate length } & \mathrm{m} \\ \mathrm{R} & : \text { substrate radius } & \mathrm{m} \\ \mathrm{L} & : \text { inlet radius } & \mathrm{m} \\ \mathrm{l} & : \text { radial length of the outlet } & \mathrm{m}\end{array}$

